\title{
Dois Lulas: a geografia eleitoral da reeleição (explorando conceitos, métodos e técnicas de análise geoespacial)
}

\author{
Gláucio Ary Dillon Soares ${ }^{1}$ \\ Instituto Universitário de Pesquisas do Rio de Janeiro \\ Sonia Luiza Terron \\ Instituto Brasileiro de Geografia e Estatística \\ Instituto Universitário de Pesquisas do Rio de Janeiro
}

\begin{abstract}
Resumo: A votação de Lula em 2006 suscitou hipóteses sobre a repercussão das políticas públicas do primeiro mandato nos resultados eleitorais. Os programas sociais de transferência direta de renda, em especial o Bolsa Família, foram associados ao grande crescimento de sua votação nos municípios mais pobres do norte e nordeste. Empregamos conceitos e métodos da geografia eleitoral moderna para averiguar qual a participação do Bolsa Família nesta mudança geográfica. Os resultados mostram um novo padrão na distribuição espacial dos votos de Lula, confirmando que este ainda recebe o apoio de suas bases anteriores, mas revelam que os blocos regionais de municípios de alta votação em 2002 perderam a coesão em 2006, tornando-se mais vulneráveis. Os resultados confirmam ainda que a participação do Bolsa Família sobre a renda local foi um determinante do novo contorno das bases geoeleitorais, e o fator de maior peso na explicação da votação municipal.
\end{abstract}

Palavras-Chave: Lula; Bolsa Família; eleição presidencial; geografia eleitoral; econometria espacial.

Abstract: The voting of Lula in 2006 excited hypotheses on the repercussion of the public politics of the first mandate in the electoral results. The social programs of direct transference of income, in special the "Bolsa Família", had been associates to the great growth of its voting in the cities poor of the north and northeast. We use concepts and methods of modern electoral geography to inquire which the participation of the "Bolsa Família" in this geographic change. The results show a new standard in the space distribution of the votes of Lula, confirming that he still receives the support from its previous bases, but disclose that the regional blocks of cities of high voting in 2002 had lost the cohesion in 2006, becoming more vulnerable. The results confirm the participation of the "Bolsa Família" on the local income was a determinative one of the new contour of the electoral-geographic basis, and the factor of big weight in the explanation of the municipal voting.

Keywords: Lula; Bolsa Família; presidential election; electoral geography; spatial econometrics.

\footnotetext{
${ }^{1}$ M.L.L., Tulane University (1959); Ph.D. em Sociologia, Washington University (1965).
} 


\section{Introdução}

As eleições de 2006 confirmaram a preferência dos brasileiros por Lula, que se reelegeu, após uma nova disputa em dois turnos, com 60,8\% dos votos válidos. O percentual significativo de aprovação suscitou várias hipóteses sobre os motivos da vitória. Muitos analistas creditaram-na aos programas sociais de transferência direta de renda, em especial ao Bolsa Família, implementados no primeiro mandato.

Nossa hipótese, semelhante às defendidas pelos que escreveram sobre o tema, é que as políticas públicas implementadas por Lula durante o primeiro mandato contaram nas eleições de 2006. Nosso percurso, entretanto, é diferente. Procuramos acrescentar, pela investigação das diferenças nas votações municipais em 2002 e 2006 e pela análise do contexto geográfico, uma explicação de como isto aconteceu. Analisamos os padrões geográficos da votação municipal e o que denominamos de coesão regional das bases geoeleitorais de 2002 e de 2006. Caracterizamos as diferenças entre essas datas e averiguamos qual a participação do Bolsa Família no grande crescimento da votação de Lula nos municípios mais pobres do norte e nordeste do país.

Comparado a 2002, o percentual de votos válidos nas regiões centro-sul do país, onde alcançava bons resultados, diminiu; e aumentou nas regiões norte e nordeste, onde o Programa Bolsa Família (BF) distribuiu mais recursos. A amplitude deste movimento de inversão geográfica facilitou a percepção da correlação. Citamos autores e argumentos que constatam a mudança da base eleitoral de Lula em 2006, quando em relação a de 2002. Há consenso quanto à mudança geográfica em direção ao norte e nordeste e à mudança no sentido inverso do desenvolvimento social de estados e municípios. Entretanto, surgiram algumas divergências quanto à utilização de métodos econométricos clássicos ou espaciais, e quanto ao dimensionamento da influência do Bolsa Família sobre os resultados eleitorais, que serão exploradas.

Tratamos dos dois enfoques: o temático, da investigação do voto em si e de sua relação com o Bolsa Família; e o metodológico, da aplicação da estatística e da econometria espacial². Usamos mapas, uma tipologia de municípios, análises estatísticas espaciais e análises de regressão com modelos espacialmente controlados. As análises exploratórias e de regressão incluíram os 5.564 municípios brasileiros $^{3}$. Para o processamento e mapeamento dos dados utilizamos os sistemas GeoDa (CSISS, 2005) e ArcView GIS (ESRI, 2000).

\footnotetext{
${ }^{2}$ A diferença entre estatística e econometria espacial segue a divisão clássica, sendo que os métodos econométricos espaciais tratam da incorporação da interação espacial e da estrutura espacial nas análises de regressão (ANSELIM, 1999).

3 A construção da base de dados foi facilitada pela cessão integral de bases de outras pesquisas (BITOUN, 2008; NICOLAU e PEIXOTO, 2007b). As fontes da informação socioeconômica, eleitoral e do
} 
SOARES, G. A. D., TERRON, S. L. Dois Lulas: a geografia eleitoral...

O artigo está organizado em cinco seções. Na primeira, sistematizamos a discussão sobre os principais argumentos e conclusões já publicados e apresentamos nossa hipótese. Em seguida, mobilizamos elementos conceituais e metodológicos da geografia eleitoral e fazemos uma investigação geográficoquantitativa da votação de Lula. Na terceira, apresentamos a análise da votação segundo a caracterização dos municípios brasileiros. Na quarta seção, avaliamos a concentração espacial e a influência do Bolsa Família na economia local. Encerramos com as análises de regressão que complementam as espaciais e com as diferenças metodológicas entre a utilização do modelo clássico de regressão e do modelo econométrico espacial.

\section{O que já sabemos sobre 2006}

Em outubro de 2006, Soares sublinhava, tomando os estados como unidade de análise, o distanciamento da votação de Lula de 2002 e de 2006; a relação entre a votação de Lula e o "SIM" no referendo; a votação maior de Lula nos estados mais pobres; e sua vitória onde os partidos tradicionais de antigamente dominavam as eleições. Soares creditou uma versão preliminar de Hunter e Power por proporcionar alguns dos dados e análises que utilizou.

$\mathrm{Na}$ versão impressa, Hunter e Power (2007) fizeram várias contribuições. $\mathrm{O}$ foco de seu trabalho é a mudança na base eleitoral de Lula. Sublinham a mudança geográfica e a mudança social: Lula passou a receber mais votos de eleitores com menor educação formal, perdendo votos entre os mais ricos e mais instruídos. Usam os estados como unidade de análise, dados de surveys e de boca-de-urna para chegar a essas conclusões. A relação com a votação do PT foi abordada pelos autores, que mostram que o distanciamento entre a votação de Lula e a votação para o PT vem de antes: as correlações (Pearson) declinaram de 0,60 em 1994, a 0,53 em 1998, 0,46 em 2002 - todas positivas e estatisticamente significativas. Em 2006, a correlação passa a ter sinal negativo, é pequena $(-0,19)$ e não atinge significância estatística. Os autores também mostram que Lula se saiu melhor do que o PT sobretudo nos estados com IDH mais baixo: em uma análise bivariada, o IDH explica $43 \%$ da sobre-votação de Lula em relação ao PT.

\footnotetext{
BF são, respectivamente, o Instituto Brasileiro de Geografia e Estatística (IBGE), o Tribunal Superior Eleitoral (TSE) e o Ministério do Desenvolvimento Social (MDS). Para os 57 municípios cuja instalação ocorreu após o Censo 2000, imputamos o valor dos indicadores socioeconômicos utilizados pelo valor do indicador no município de origem (caso de um só município) ou calculamos a média dos valores dos indicadores (caso de mais de um município de origem). Em todas as análises eleitorais tomamos o $2^{\circ}$ turno, e a proporção de votos nominais sobre o total de votos válidos (nominais, brancos e nulos). Os resultados referem-se a tendências da população e do eleitorado municipal, e não a comportamentos individuais A inferência de comportamento individual através de agregações é um problema estatístico conhecido como falácia ecológica.
} 
Concordam com Soares em que somente no segundo turno dessas eleições a votação de Lula se aproximou do que as teorias macro-estruturais previam para um candidato de esquerda. Essas mudanças se refletiram geograficamente, com Lula ganhando folgadamente no nordeste e no norte. Especificamente, Lula passou a dominar os antigos grotões, sendo a distribuição da sua votação semelhante à obtida por Collor em 1989. Nessa análise "macro", usaram dados socioeconômicos agregados e estatísticas oficiais das eleições.

Finalmente, Hunter e Power entram no campo das percepções e avaliações ao discutirem os escândalos do governo Lula. Os mais pobres estariam menos informados e, quando informados, dariam menos relevância a eles. Citam pesquisa que mostrou que no nordeste $43 \%$ dos entrevistados aceitavam estar desinformados sobre o tema, em contraste com apenas $25 \%$ no sudeste.

Santos (2006) concorda com a mudança na geografia do voto dado a Lula em 2006, mas afasta qualquer interpretação que conduza à afirmação de que os novos eleitores de Lula pertencem aos "grotões" da política brasileira. Esse termo era usado para descrever as áreas que apoiavam os partidos conservadores, inclusive os favoráveis à ditadura militar. Sua posição é de que os antigos "grotões" mudaram e hoje são mais politizados e ideológicos, inclusive mais urbanos. Embora sem nomear explicitamente, as críticas de Santos se dirigem a Soares e a Hunter e Power.

Nicolau e Peixoto (2007a), utilizando base de dados municipais, relacionam a percentagem dos votos recebidos por Lula nas quatro votações com o tamanho da população dos municípios. Em 2002, o percentual aumentou com o tamanho; em 2006, a faixa onde Lula recebeu percentagens mais altas foi nos municípios com entre 10 e 20 mil habitantes. Assim, inferem, através do tamanho da população municipal, que o padrão analítico entre urbanização e os votos em Lula foi alterado; retomam, mais adiante, as relações com macro-covariatas e constatam que, em todas as análises, o sinal da correlação se inverteu.

Os dois autores também analisaram a relação entre necessidade social e a extensão do Programa Bolsa-Família, concluindo que a associação era positiva: "Os dados revelam uma forte associação negativa entre os dois indicadores $(r=-0,83)$. Ou seja, quanto mais pobre é o município, mais recursos per capita ele recebeu do Bolsa Família." Em seguida, expandem a análise relacionando o BF e a votação em Lula:

"A associação entre o percentual de votos obtidos por Lula e os gastos do Bolsa Familia é expressiva: $r=0,72$ no primeiro turno e $r=0,69$ no segundo turno. Esses números indicam que Lula obteve percentualmente mais votos nos municípios que receberam mais recursos per capita do Bolsa Família" (NICOLAU e PEIXOTO, 2007a, p.21). 
Usando toda a bateria de variáveis, concluem que ela explica $63 \%$ na variância da votação de Lula. Num segundo artigo, os autores reforçaram as análises e conclusões do primeiro, usando um elenco de indicadores sociais mais selecionado e substituindo nas regressões o IDHM-Renda 2000 pela Renda média mensal domiciliar per capita 2000. Os resultados reiteram que: "o grau de desenvolvimento social, os valores do programa Bolsa Família e a região em que o município se situa foram fundamentais para explicar a variação dos votos na disputa presidencial" (NICOLAU e PEIXOTO, 2007c, p.17).

Carraro et al (2007), em estudo com clara preocupação econométrica, concordam com a tese de que, em 2006, Lula foi mais votado nos municípios menos desenvolvidos do Brasil e concluem que essa votação estava negativamente correlacionada com a renda per capita do município e diretamente correlacionada com a taxa mortalidade infantil, analfabetismo e a desigualdade. Todavia, estes autores discordam dos métodos de Nicolau e Peixoto por terem ignorado os efeitos espaciais quando pretenderam resolver o problema com dummies regionais. Também criticam discretamente Hunter e Power por afirmarem que "os pobres teriam votado em Lula por ignorância ou indiferença frente às acusações de corrupção."

O modelo seguido é mais complexo, com mais atenção à análise espacial. Começam com análise que chamam de "modelo clássico" que permite concluir que:

"Os resultados indicam que a votação de Lula é sempre inelástica nas variáveis. A maior delas, em valor absoluto, é a renda per capita (e é a única cuja relação é inversa: um aumento de $1 \%$ na renda per capita diminui a votação do candidato em $-0.154 \%$ ), seguida pelas proxies de desigualdade (relação positiva com os votos recebidos pelo candidato), Bolsa Família, densidade demográfica, mortalidade infantil, analfabetismo e distância da capital do estado" (CARRARO et al, 2007).

Porém, testando esse modelo, constatam a existência de auto-correlações espaciais. Optam pelo modelo de erro espacial, que produz melhores resultados do que o do lag espacial, segundo o teste estatístico do multiplicador de Lagrange. Criticando Nicolau e Peixoto, argumentam que a percentagem de pobres no município é um dado importante e calculam o BF a partir dessa subpopulação. A partir dessa lógica, criam duas variáveis, os atendidos pelo programa em relação à população pobre e em relação à população indigente. Comparando os três modelos usados, o modelo que usa o BF sobre o total da população produz melhores resultados (considerando o valor de $p$ ), sendo que o modelo baseado no BF sobre a população indigente não produz um resultado significativo para essa variável. Concluem que "esses resultados fazem com que o impacto positivo do Bolsa 
Família, com os devidos controles, não seja tão espetacular e confiável estatisticamente quanto poderia parecer numa primeira análise" (CARRARO et al, 2007) Os autores sublinham que as elasticidades são baixas.

O trabalho agrega outras considerações importantes, típicas de economistas: a inflação foi menor no nível de renda da cesta básica do que nos mais altos; a desigualdade foi reduzida. Os autores testaram também o impacto do aumento das exportações, proposto por Pessoa (apud CARRARO et al, 2007), que não foi observado no nível dos estados.

Marques et al (2007) analisaram os resultados das eleições usando os municípios e os estados como unidades de observação para aferir se o Bolsa Família influiu na votação de Lula e concluíram que houve entre ambos uma clara associação positiva. Zucco (2006) também concluiu que a percentagem da votação dada a Lula em 2002 não se correlaciona com a de 2006: tomando como unidade de análise os estados, a correlação do IDH com a votação em 2002 era moderadamente positiva, mas a de 2006 passou a ser claramente negativa. Usando regressões OLS em sete modelos, concluiu que o Bolsa Família foi um importante fator para a eleição de Lula. Em trabalho posterior, expandiu a análise para o nível municipal e confirmou esses resultados. Assim, este autor discorda do argumento de Carraro et al (2007) de que foi a performance econômica ao invés do programa Bolsa Família que causou a mudança na base eleitoral de Lula (ZUCCO, 2008).

Há, em geral, um consenso sobre a tese da mudança das bases eleitorais de Lula, que em 2006 teria sido mais votado nos municípios menos desenvolvidos. À exceção de Carrarro et al, os autores anteriormente citados concordam que a influência do BF foi significativa para essa mudança e para a vitória de Lula. Carraro et al introduziram a análise espacial por município no estudo da votação de Lula e contestaram os resultados obtidos por Nicolau e Peixoto, com base em preceitos metodológicos. Aproveitamos essa oportunidade para aprofundar a discussão metodológica na seção das inferências.

As análises de eleições e de reeleições não são iguais. Na reeleição, o voto pode ter vinculação com o desempenho anterior do candidato; há elementos informativos e cognitivos disponíveis para uma avaliação baseada no desempenho (SOARES, 2000). Nossa hipótese, semelhante às defendidas pelos que escreveram sobre o tema, é que as políticas públicas implementadas por Lula entre 2002 e 2006 contaram nas eleições de 2006 e uma das mais importantes e conhecidas, tanto pelo montante das transferências quanto pela publicidade, é o Bolsa Família.

Como, em vários sentidos, esse é um programa de transferência de renda, a teoria dos interesses postularia que seu efeito seria positivo entre os beneficiários, mas poderia ser negativo entre os que se perceberam pagando por ele, através de seus impostos. Esses são os efeitos diretos, aos quais devemos agregar os indiretos, de pessoas afetadas secundariamente pelo programa e suas percepções. 
SOARES, G. A. D., TERRON, S. L. Dois Lulas: a geografia eleitoral...

Esses efeitos indiretos são postulados pela teoria do contextualismo geográfico, para a qual o comportamento eleitoral sofre a influência do ambiente sóciogeográfico, quer pela ação de redes de interação social, quer pelas experiências inerentes ao próprio local em que se vive.

\section{Contexto geográfico e coesão regional}

Distante quase um século de suas origens francesas, uma tradição que combinava mapas e alguma análise estatística, a geografia eleitoral contemporânea procura descobrir porque determinados partidos e candidatos recebem maior apoio eleitoral de alguns lugares do que de outros pela análise de fatores que interagem de maneira complexa. Para Pattie e Johnston (2006), a geografia social dos partidos, as interações entre os cidadãos que moram nas mesmas áreas, o impacto da economia nacional e local na popularidade do governo e as campanhas eleitorais geograficamente orientadas são alguns dos principais.

A investigação desses fatores provocou um debate ${ }^{4}$ sobre a importância relativa dos efeitos contextuais (espacialmente estruturados pelo ambiente em que vivem, pelas coisas que vêem e experimentam e pelos encontros que têm ao longo da vida) e composicionais (baseados nos grupos sociais a que pertencem, nas suas criações e aquisições ao longo da vida): as pessoas se comportam e pensam de acordo com o que são (efeitos composicionais), ou por causa de onde estão (efeitos contextuais)? "Os dois" é a resposta mais fácil que elude a resolução do problema. Se os dois, em que medida?

Os proponentes da importância dos efeitos contextuais, ou do contextualismo, apresentam uma contrapartida ao individualismo ontológico, que foca o indivíduo como ator racional que age sempre em seu interesse e que, mesmo agregado, comporta-se de modo independente dos demais indivíduos e de seu contexto. Os "contextualistas" afirmam que a política não pode ser compreendida fora do contexto em que ocorre.

Essa questão distingue cientistas políticos e sociais de geógrafos políticos: uns mais propensos a aceitar que o contexto influencia o comportamento eleitoral através das redes de interação social, quer entre amigos e vizinhos ou entre ambientes homogêneos ou heterogêneos; e outros que procuram mostrar que o contexto geográfico é mais relevante do que a interação social. Entretanto, a geografia de qualquer eleição é uma combinação de ambos os efeitos, composicional e contextual, e nossa principal tarefa é revelar como isto acontece.

\footnotetext{
${ }^{4}$ Ethington e McDaniel (2007) apresentam uma síntese dessa discussão, além de uma relação exaustiva de referências bibliográficas relacionadas ao tema. Ver também Pattie e Johnston, 2006 e Zuckerman, 2005.
} 
Nosso primeiro passo para identificação de possíveis influências de contexto(s) geográfico(s), ou efeitos locais e regionais na votação de Lula em 2006, é a identificação de regiões relativamente homogêneas em relação à escolha eleitoral. Os padrões espaciais de 2002 e de 2006 são completamente diferentes. Nos mapas a seguir, se o distrito eleitoral fosse o município, Lula seria eleito em todos aqueles das duas classes superiores da legenda (de cores mais escuras), onde ele alcançou mais de $50 \%$ dos votos válidos no segundo turno. Apesar da escala, é possível observar que o padrão espacial se assemelha ao de um mosaico no mapa de 2002, com poucas regiões homogêneas em extensão territorial. O padrão de 2006, entretanto, é visivelmente concentrado e regional.

\section{Mapa 1}

\section{PADRŐESESPACIAIS DA VOTAÇÄO DE LULA 2006 E 2002}

(\% Votos por Município - $2^{\circ}$ Turno)

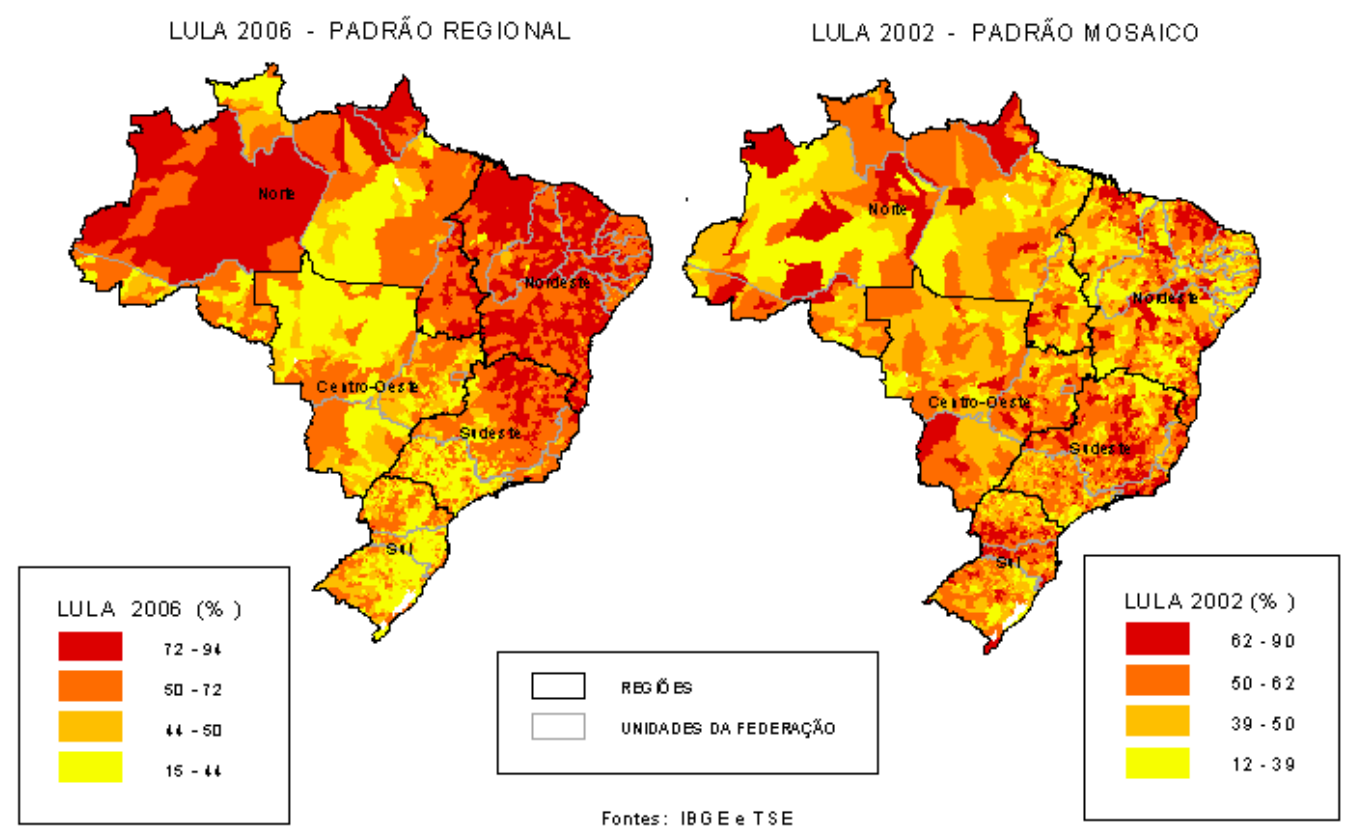


SOARES, G. A. D., TERRON, S. L. Dois Lulas: a geografia eleitoral...

O conceito-chave das análises geográficas é a auto-correlação espacial ${ }^{5}$. O índice global de Moran estima a magnitude da auto-correlação espacial, e pode ser desagregado em Indicadores Locais de Auto-correlação Espacial - ILAE (Local Indicator of Spatial Correlation - LISA) ou Moran Local, que identificam a existência de diferentes regimes de correlação em sub-regiões distintas. Estes índices, bem com as demais estatísticas espaciais, dependem da definição de uma vizinhança para estimar a variabilidade espacial dos dados.

A matriz de vizinhança é a chave para a inserção das relações espaciais nestes modelos. A maioria dos softwares de análise geoespacial tem rotinas para sua construção com base em critérios de distância ou contigüidade. Criamos uma matriz de vizinhança baseada no critério de contigüidade, no qual um município é vizinho do outro quando compartilha com ele um limite em comum. Esta matriz será utilizada em todas as estatísticas espaciais.

Medimos a auto-correlação espacial do percentual de votos de Lula nos municípios pelo índice de Moran I. Os valores de Moran I situam-se no intervalo entre 1, auto-correlação espacial positiva máxima, e-1, auto-correlação espacial negativa máxima; sendo 0 a ausência de auto-correlação espacial (SMITH et al, 2007). A Tabela 1 mostra que os índices dos dois turnos aumentaram significativamente de 2002 para 2006 (a significância foi estimada por randomização ${ }^{6}$ ). Os valores indicam o quanto a votação no município pode estar associada à votação nos municípios vizinhos e mostram que os municípios se agruparam mais em torno da votação de Lula nesta última eleição.

\section{Tabela 1 - Valores do Índice Moran I para os percentuais de voto de Lula, em 2002 e $2006 *$}

\begin{tabular}{|c|c|c|c|c|}
\hline & $2006 \cdot 1^{\circ} \mathrm{T}$ & $2006 \cdot 2^{\circ} T$ & $2002 \cdot 1^{\circ} \mathrm{T}$ & $2002 \cdot 2^{\circ} T$ \\
\hline Lula & 0,7998 & 0,8067 & 0,5988 & 0,5353 \\
\hline
\end{tabular}

\footnotetext{
5 Segundo Smith et al, auto-correlação espacial é o "grau da relação que existe entre duas ou mais variáveis espaciais, de modo que quando uma muda, a(s) outra(s) também muda(m). A mudança pode ser tanto na mesma direção, o que significa uma auto-correlação positiva, quanto em direção oposta, que caracteriza uma auto-correlação negativa" (SMITH et al, 2007, p.15, tradução dos autores).

$6 \mathrm{Na}$ randomização, processamos 9.999 permutações das observações e dos locais e calculamos a probabilidade da ocorrência do atual I das 10.000 amostras (as 9.999 permutações mais o I atual).
} 
Calculamos os Indicadores Locais para identificar que municípios pertencem aos grupamentos (clusters) locais ou regionais com votação semelhante, os quais denominamos bases geoeleitorais. Os índices de Moran Local classificam os resultados com significância estatística em quatro categorias: alto-alto, baixo-baixo, alto-baixo e baixo-alto. O primeiro indicador qualifica a votação do município em relação à média da vizinhança (conjunto de municípios definidos na matriz de vizinhaça), e o segundo qualifica a vizinhança em relação à média nacional. $\mathrm{Na}$ categoria alto-alto, por exemplo, encontram-se municípios com votação forte, localizados em áreas onde o apoio local também é alto. As demais categorias são interpretadas por analogia.

Mapeamos os resultados de Moran Local para o $2^{\circ}$ turno de Lula em 2002 e 2006 (Mapa 2). As manchas em verde escuro, formadas pelos municípios de votação do tipo alto-alto, delimitam as bases geoeleitorais que se diferenciam regionalmente pelo apoio forte a Lula. As áreas em amarelo, dos municípios com votação do tipo baixo-baixo, representam as bases geoeleitorais onde o seu apoio regional é fraco. Como analisamos o segundo turno, os dois casos referem-se também a uma oposição fraca ou forte, respectivamente. Estes blocos de municípios representam uma coesão regional em torno do apoio, mais ou menos forte, ao candidato. Em contrapartida, as áreas em branco, onde não houve significância estatística, representam uma certa vulnerabilidade regional onde o candidato, apesar de alcançar escores altos em determinados municípios, não é tão bem sucedido nos municípios vizinhos. Na votação de Lula, tanto as zonas de coesão quanto as de vulnerabilidade mudaram de 2002 para 2006.

Em 2002, Lula conseguiu uma coesão regional significativa em torno de regiões metropolitanas importantes como a do Rio de Janeiro (que se estendeu pela maioria dos municípios fluminense e do sudeste de Minas Gerais), de Belo Horizonte (MG), de Fortaleza (CE), de Salvador (BA) e de Manaus (AM), dentre outras menores. Os municípios do estado do Amapá e os do sul do Paraná - oeste de Santa Catarina também se agruparam como bases geoeleitorais fortes. Nesta eleição, 816 municípios das bases geoeleitorais tipo alto-alto contribuíram com 40,9\% dos votos de Lula (Tabela 2a). Praticamente o mesmo percentual de municípios formou regiões coesas em baixa votação (baixa-baixa) mas, como são municípios menos populosos, representaram apenas $5 \%$ dos votos válidos. 
Mapa 2 - Distribuição das categorias de Moran Local da Votação de Lula por município no $2^{\circ}$ turno de 2002 e 2006

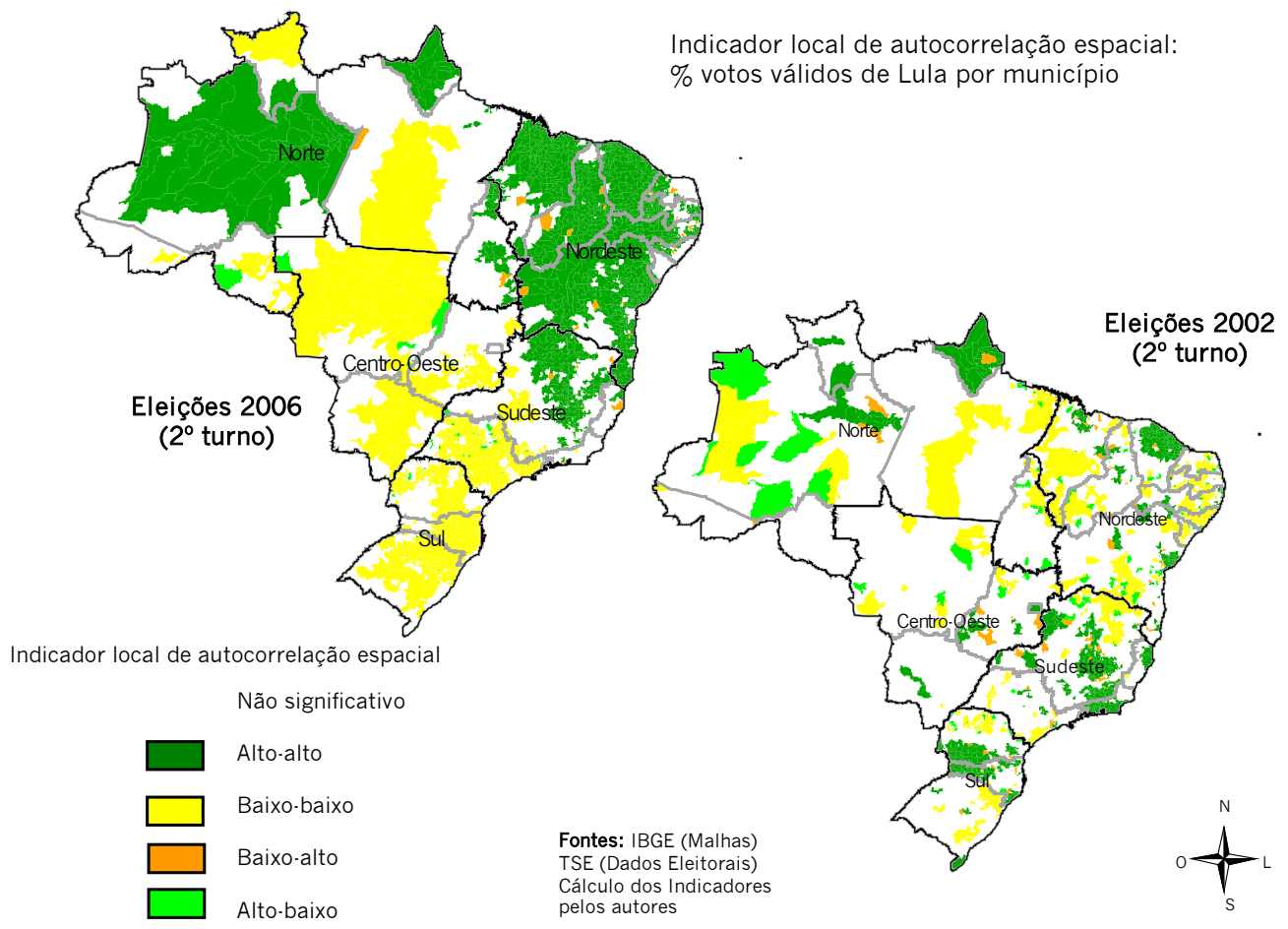

Tabela 2a - Número de municípios, votos válidos (\%) e votos em Lula (\%) no $2^{\circ}$ turno de 2002 , segundo as categorias de Moran Local

\begin{tabular}{|l|c|c|c|c|}
\hline Agrupamentos & Municípios & $\begin{array}{c}\text { Municípios } \\
\%\end{array}$ & $\begin{array}{c}\text { Válidos 02 } \\
\%\end{array}$ & $\begin{array}{c}\text { Lula 2002 } \\
(\%)\end{array}$ \\
\hline Alto - Alto & 816 & 14,7 & 33,7 & 40,9 \\
\hline Baixo Baixo & 784 & 14,1 & 7,5 & 5,0 \\
\hline Baixo- Alto & 68 & 1,2 & 7,7 & 6,4 \\
\hline Alto- Baixo & 92 & 1,7 & 1,8 & 1,7 \\
\hline Não Significativo & 3804 & 68,4 & 49,4 & 46,0 \\
\hline
\end{tabular}

Fontes: TSE, IBGE, processamento dos autores. 
Em 2006, é possível distinguir três grandes blocos territoriais de alta votação (centro-norte de Minas Gerais e região nordeste, estado do Amapá e estado do Amazonas) e três outros de baixa (estado de São Paulo, região sul, e região centro-oeste e municípios do Pará). Em termos quantitativos (Tabelas 2b), as regiões de coesão (alto-alto e baixo-baixo) aumentaram em número de municípios e extensão territorial em relação a 2002. Entretanto, as bases geoeleitorais coesas de Lula contribuíram menos, com 33,8\%, do que em 2002 (40,9\%). Já a coesão regional da oposição aumentou de $5,0 \%$ para $16,1 \%$ em votos.

Tabela 2b - Número de municípios, votos válidos (\%) e votos em Lula (\%) no $2^{\circ}$ turno de 2006 , segundo as categorias de Moran Local

\begin{tabular}{|l|c|c|c|c|}
\hline Agrupamentos & Municípios & $\begin{array}{c}\text { Municípios } \\
(\%)\end{array}$ & $\begin{array}{c}\text { Válidos } \\
2006(\%)\end{array}$ & $\begin{array}{c}\text { Lula 2006 } \\
(\%)\end{array}$ \\
\hline Alto - Alto & 1543 & 27,7 & 26,0 & 33,8 \\
\hline Baixo Baixo & 1456 & 26,2 & 22,7 & 16,1 \\
\hline Baixo- Alto & 37 & 0,7 & 4,2 & 4,2 \\
\hline Alto- Baixo & 35 & 0,6 & 0,3 & 0,3 \\
\hline $\begin{array}{l}\text { Não } \\
\text { Significativo }\end{array}$ & 2493 & 44,8 & 46,8 & 45,5 \\
\hline
\end{tabular}

Fontes: TSE, IBGE, processamento dos autores.

Somados os votos válidos referentes às categorias 1 e 2 (alto-alto e baixobaixo) da votação de Lula, obtemos 41,2\% e 48,7\% em 2002 e 2006, respectivamente. Significa uma grande capacidade de Lula na mobilização de bases geoeleitorais, tanto a favor como contra sua política, formando regiões que ultrapassam as fronteiras municipais e até estaduais. Segundo a lógica do contextualismo, a expectativa seria de que, nas zonas de coesão, o candidato mais votado na eleição anterior tivesse maiores chances de manter essa maioria e, nas zonas de vulnerabilidade, maiores chances de perdê-la. Analisamos a dinâmica 2002 - 2006 das bases geoeleitorais de Lula em quatro situações (Tabela 3):

- Coesão regional e manutenção - municípios do tipo alto-alto (apoio regional forte) ou baixo-baixo (apoio regional fraco ou oposição forte) que se mantiveram na mesma categoria nas duas eleições;

- Coesão regional e alteração - municípios de apoio ou oposição regional que trocaram de categoria de uma eleição para outra;

- Dissolução da coesão regional - municípios de apoio ou oposição regional que passaram para a zona de vulnerabilidade (não apresentaram significância estatística); 
SOARES, G. A. D., TERRON, S. L. Dois Lulas: a geografia eleitoral...

- Construção da coesão regional - municípios que passaram da zona de vulnerabilidade para zonas de apoio ou oposição regional;

- Manutenção da vulnerabilidade regional - municípios sem significância estatística de Moran local em 2002 e que permaneceram assim em 2006.

Tabela 3 - Dinâmica das Bases Geoeleitorais de Lula

\begin{tabular}{|l|l|l|l|l|}
\hline $\begin{array}{l}\text { Dinâmica das Bases } \\
\text { GeoEleitorais }\end{array}$ & Municípios & $\begin{array}{c}\text { (\%) } \\
\text { Municípios }\end{array}$ & Pop. 2006 & $\begin{array}{c}\text { (\%) } \\
\text { Pop. 2006 }\end{array}$ \\
\hline Coesão Regional e Manutenção & 472 & 8,5 & 29.182 .872 & 15,8 \\
\hline Coesão Regional e Alteração & 317 & 5,7 & 7.292 .620 & 4,0 \\
\hline Dissolução da Coesão Regional & 811 & 14,6 & 38.817 .321 & 21,1 \\
\hline Construção da Coesão Regional & 2.210 & 39,7 & 53.975 .577 & 29,3 \\
\hline $\begin{array}{l}\text { Manutenção da Vulnerabilidade } \\
\text { Regional }\end{array}$ & 1.754 & 31,5 & 54.915 .874 & 29,8 \\
\hline & 5.564 & 100,0 & 184.184 .264 & 100,0 \\
\hline
\end{tabular}

Fontes: TSE, IBGE, processamento dos autores.

Segundo esta avaliação, 14,2 \% dos municípios ou cerca de um quinto da população em 2006 (19,8\%) manteve uma situação de coesão regional. Destes, a maioria se manteve fiel à decisão tomada em 2002, seja de apoio ou de oposição. Outros $21,15 \%$ da população, em $14,6 \%$ dos municípios, romperam com a coesão regional. Um número significativo de municípios (39,7\%), com 29,3\% da população, construiu novas zonas de coesão de apoio ou de oposição. Donde concluímos:

- Houve um reordenamento e uma regionalização significativa do apoio eleitoral em grandes proporções territoriais. Estas proporções dificilmente seriam alcançadas em quatro anos sem a ajuda de um fator socioeconômico diferenciado regionalmente. Este movimento talvez não tenha sido forte o suficiente para, sozinho, decidir a eleição de 2006 , ou para dissolver as bases geoeleitorais de Lula em 2002.

- No norte e nordeste, onde foram construídas novas zonas de coesão, o movimento não conseguiu arrematar as bases de oposição de 2002, que passaram para a situação de vulnerabilidade, mas manteve as que já tinha em 2002 e conquistou grande parte das vulneráveis. Esta nova coesão regional é, provavelmente, decorrente da implementação dos programas sociais de transferência de renda, em especial o Bolsa Família.

- Na região centro-sul, houve um movimento de desconstrução de bases fortes de 2002, que não necessariamente retiraram o apoio a Lula, mas perderam a coesão regional em torno dele, passando para uma situação 
de vulnerabilidade. Houve também a construção de extensas (territorialmente) regiões de oposição nos municípios que eram vulneráveis em 2002. Há necessidade de caracterização socioeconômica destes municípios.

\section{Caracterização das bases geoeleitorais}

Num país como o Brasil, as dimensões territoriais e as diversidades socioeconômicas e culturais são determinantes para a análise. São aproximadamente 8,5 milhões de $\mathrm{km}^{2}$, uma população de 183.987.291 habitantes, segundo a mais recente contagem da população (IBGE, 2007) e um mosaico de 5.564 municípios. A maior parte da população vive nas aglomerações urbanas e a divisão territorial brasileira reflete um quadro complexo e fragmentado. Para caracterização do eleitorado de Lula, trazemos a proposta de tipologia das cidades brasileiras (PPGEO-UFPE e FASE, 2005), estudo realizado a pedido do Ministério das Cidades, que procurou integrar em uma única classificação espaços urbanos e rurais e evidenciar a diversidade das relações existentes entre cidades e territórios. Foram classificados 19 tipos que caracterizam as aglomerações urbanas, os centros urbanos e as pequenas cidades de acordo com sua situação socioeconômica e a do espaço rural em que se localizam. Para a análise eleitoral, agregamos em 6 categorias $^{7}$ os 19 tipos originais (relacionados entre parênteses) conforme a seguir:

1) Grande Urbano (Centro-Sul): espaços urbanos aglomerados e centros regionais do centro-sul (tipos 1 e 3);

2) Grande Urbano (Norte e Nordeste): espaços urbanos aglomerados e centros regionais do norte e nordeste (tipos 2 e 4);

3) Médio Urbano em Rural Próspero: centros urbanos em espaços rurais prósperos (tipos 5 e 6) ou que vêm enriquecendo, predominantemente no centro-sul (tipo 9);

4) Médio Urbano em Rural Misto: centros urbanos em espaços rurais consolidados (tipos 7 e 8), em espaços rurais que vêm enriquecendo na fronteira agrícola, com alta desigualdade (tipo 10), em espaços rurais no sertão nordestino e da Amazônia (tipo 11), em espaços rurais pobres com alta densidade populacional perto dos grandes centros (tipo 12) e em espaços rurais pobres e relativamente isolados (tipo 13);

\footnotetext{
7 A agregação não define uma nova tipologia, pois é a classificação nos 19 tipos originais (PPGEO-UFPE e FASE, 2005) que captura a diversidade das relações existentes entre cidades e territórios.
} 
5) Pequeno Urbano em Rural Próspero: pequenas cidades em espaços rurais prósperos (tipo 14 e 15);

6) Pequeno Urbano em Rural Misto: pequenas cidades em espaços rurais consolidados ou de pouca densidade econômica (tipo 16 a 19).

Apresentamos em cores diferenciadas as seis categorias de municípios (Mapa 3). Os tons de vermelho e amarelo diferenciam espaços rurais prósperos de espaços rurais mistos (verde). As gradações de cada tom diferenciam o tamanho dos centros urbanos.

As categorias mais prósperas (1, 3 e 5 ) apresentaram médias mais altas dos rendimentos domiciliares médios mensais per capita e dos IDHM 2000 em relação ao conjunto menos próspero de municípios, como pode ser observado na Tabela 4. O mapeamento da tipologia representa espacialmente a grande clivagem socioeconômica dos municípios brasileiros que, na metodologia tradicional, os analistas procuram capturar através de dummies regionais incluídas nos modelos de regressão.

\section{Mapa 3 - Tipologia das Cidades Brasileiras adaptada para 6 categorias}

Regiões Geográficas e Tipologia de Municípios Brasileiros

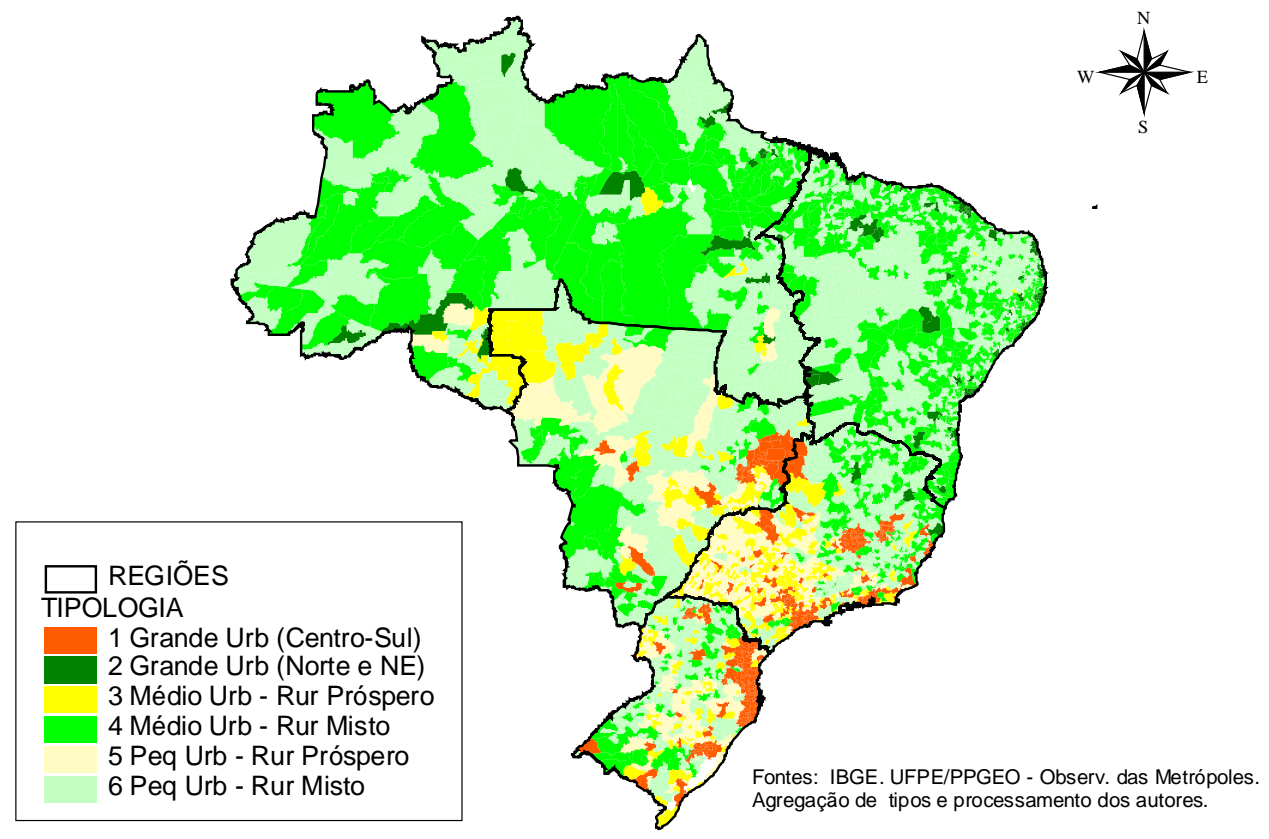


Tabela 4 - Número de municípios e população estimada (2006), média do rendimento mensal domiciliar per capita (2000) e do IDHM (2000), por tipo agregado da Tipologia das Cidades Brasileiras

\begin{tabular}{|l|c|c|c|c|}
\hline Tipologia & $\begin{array}{c}\text { Municípios } \\
2006\end{array}$ & $\begin{array}{c}\text { Pop. estim } \\
2006\end{array}$ & $\begin{array}{c}\text { Rendapc } \\
2000 \\
\text { média * }\end{array}$ & $\begin{array}{c}\text { Idhm 2000 } \\
\text { média * }\end{array}$ \\
\hline $\begin{array}{l}\text { 1 Grande Urbano } \\
\text { (Centro-Sul) }\end{array}$ & $\begin{array}{c}460 \\
(8,3 \%)\end{array}$ & $\begin{array}{c}78.265 .935 \\
(42,5 \%)\end{array}$ & 287,74 & 0,782 \\
\hline $\begin{array}{l}\text { 2 Grande Urbano } \\
\text { (Norte e Nordeste) }\end{array}$ & $\begin{array}{c}121 \\
(2,2 \%)\end{array}$ & $\begin{array}{c}28.178 .845 \\
(15,3 \%)\end{array}$ & 165,55 & 0,705 \\
\hline $\begin{array}{l}\text { 3 Médio Urbano } \\
\text { (Rural Próspero) }\end{array}$ & $\begin{array}{c}323 \\
(5,8 \%)\end{array}$ & $\begin{array}{c}13.896 .097 \\
(7,5 \%)\end{array}$ & 295,48 & 0,786 \\
\hline $\begin{array}{l}\text { 4 Médio Urbano } \\
\text { (Rural Misto) }\end{array}$ & $\begin{array}{c}806 \\
(14,5 \%)\end{array}$ & $\begin{array}{c}31.185 .322 \\
(16,9 \%)\end{array}$ & 133,49 & 0,664 \\
\hline $\begin{array}{l}\text { 5 Pequeno Urbano } \\
\text { (Rural Próspero) }\end{array}$ & $\begin{array}{c}996 \\
(17,9 \%)\end{array}$ & $\begin{array}{c}7.291 .523 \\
(4,0 \%)\end{array}$ & 243,26 & 0,772 \\
\hline $\begin{array}{l}\text { 6 Pequeno Urbano } \\
\text { (Rural Misto) }\end{array}$ & $\begin{array}{c}2858 \\
(51,4 \%)\end{array}$ & $\begin{array}{c}25.366 .542 \\
(13,8 \%)\end{array}$ & 125,06 & 0,662 \\
\cline { 2 - 4 } & 5.564 & 184.184 .264 & &
\end{tabular}

* Média destes indicadores nos municípios da categoria.

Fontes: PPGEO/UFPE - FASE, TSE, processamento dos autores.

$\mathrm{Na}$ Tabela 5, apresentamos a média da proporção de votos de Lula segundo os seis tipos. Em 2002, sua melhor performance foi nos grandes municípios urbanos, tanto no centro-sul, quanto no norte e nordeste (tipos 1 e 2), seguida pelos centros urbanos médios e pelas pequenas cidades situadas em espaços rurais mais prósperos. Em 2006, a situação se inverte: a média sobe muito nos grandes centros urbanos do norte e nordeste (tipo 2) e nos municípios de cidades médias e pequenas, situadas em espaços rurais consolidados, estagnados ou mais pobres (tipos 4 e 6).

Tabela 5 - Votos de Lula no $2^{\circ}$ turno das eleições presidenciais 2006 e 2002 , e a diferença, por tipo agregado da Tipologia das Cidades Brasileiras (\%)

\begin{tabular}{|l|c|c|c|}
\hline Tipologia & Lula 2006 (\%) & Lula 2002 (\%) & Diferença \\
\hline 1 Grande Urbano (Centro-Sul) & 38,4 & 44,2 & $.5,8$ \\
\hline 2 Grande Urbano (Norte e Nordeste) & 57,3 & 41,4 & 15,9 \\
\hline 3 Médio Urbano - Rural Próspero & 33,1 & 39,8 & $-6,7$ \\
\hline 4 Médio Urbano - Rural Misto & 55,2 & 34,8 & 20,4 \\
\hline 5 Pequeno Urbano - Rural Próspero & 33,9 & 39,7 & $.5,8$ \\
\hline 6 Pequeno Urbano - Rural Misto & 51,0 & 33,6 & 17,4 \\
\hline
\end{tabular}

Fontes: PPGEO/UFPE - FASE, TSE, processamento dos autores. 
SOARES, G. A. D., TERRON, S. L. Dois Lulas: a geografia eleitoral...

A votação de Lula mudou para uma maior diferenciação espacial. O desvio padrão ajuda a dimensionar esta diferenciação: em 2002 era 4,02 e em 2006 aumentou para 10,95; o mínimo e o máximo em 2002 eram 33,6 e 44,2, e, respectivamente, em 2006, passaram a 33,1 e 57,3. Donde concluímos:

- Há tendências bem diferenciadas na concentração sócio-geográfica dos votos. Em 2002, a votação alta se concentrava nos centros urbanos de grande e médio portes localizados em espaços rurais prósperos; e, em 2006, em cidades de médio e pequeno portes situadas em ambiente rural misto, estagnados, pobres ou que apresentam crescimento com alta desigualdade social.

- Há que se dimensionar, entretanto, se estas mudanças são tendências nacionais, refletindo uma mudança estrutural do eleitorado de Lula, ou regionais, provavelmente decorrentes dos programas sociais.

\section{O Bolsa Família e a nova coesão regional}

Uma avaliação segundo a teoria dos interesses, baseada no desempenho do candidato em seu mandato anterior, postularia que o efeito direto do programa sobre o comportamento eleitoral seria positivo entre os beneficiários do Bolsa Família. Segundo o contextualismo, seria também entre aqueles que se beneficiam indiretamente do Programa devido à contribuição deste à economia local, e para aqueles que tendem a acatar a opinião da maioria.

O Bolsa-Família ${ }^{8}$ distribuiu recursos regionalmente diferenciados. As regiões nordeste e sudeste foram as mais contempladas em 2006, em recursos e em número de famílias (Tabela 6 ). O sudeste fica em segundo lugar por ser a região mais populosa do país.

\footnotetext{
8 As informações oficiais do programa estão disponíveis em: <www.mds.gov.br>, Ministério do Desenvolvimento Social e Combate à Fome (MDS). Programa Bolsa Família. Em quatro anos, de 2003 a 2006, os investimentos passaram de $\mathrm{R} \$ 570$ milhões para $\mathrm{R} \$ 7,5$ bilhões, num total acumulado de R \$17,6 bilhões. Iniciou com 3,6 milhões de famílias em 2003 e chegou a aproximadamente 11 milhões em 2006 (NICOLAU e PEIXOTO, 2007a).
} 
Tabela 6 - Benefícios transferidos, famílias atendidas, e média mensal de benefício por família do BF, 2006

\begin{tabular}{|l|c|c|c|c|c|}
\hline Região & $\begin{array}{c}\text { Benefícios } \\
\text { (bilhões R\$) }\end{array}$ & Benefícios (\%) & Famílias (mil) & $\begin{array}{c}\text { Famílias } \\
(\%)\end{array}$ & $\begin{array}{c}\text { Benef/Fam } \\
\text { mensal (R\$) }\end{array}$ \\
\hline $\mathrm{N}$ & 0,73 & 9,8 & 1024 & 9,3 & 59,75 \\
\hline $\mathrm{NE}$ & 3,94 & 52,5 & 5443 & 49,6 & 60,45 \\
\hline $\mathrm{SE}$ & 1,82 & 24,2 & 2876 & 26,2 & 52,68 \\
\hline $\mathrm{S}$ & 0,67 & 8,9 & 1027 & 9,4 & 54,59 \\
\hline CO & 0,35 & 4,7 & 597 & 5,4 & 49,16 \\
\hline Total Brasil & 7,53 & 100,0 & 10966 & 100,0 & 57,18 \\
\hline
\end{tabular}

Fonte: MDS, Nicolau e Peixoto (2007a; 2007b; 2007c), TSE. Processamento dos autores.

A Pesquisa Nacional por Amostra de Domicílios (PNAD) $2006^{9}$ investigou a cobertura dos programas sociais e registrou os índices mais altos no nordeste e os mais baixos no sudeste. Segundo a PNAD, as transferências, no geral, atingiram os grupos familiares com rendimentos mais baixos. A pesquisa estimou em $R \$ 601,00$ o rendimento médio mensal domiciliar per capita em 2006, sendo $R \$ 172,00$ para os domicílios em que havia recebimento de benefícios, e R $\$ 699,00$ para os que não havia. Este comportamento foi similar também nos estados.

Soares, Veras e Ribas ${ }^{10}$ comparam o Bolsa Família em 2004 e 2006 no que tange à focalização e cobertura, utilizando dados da PNAD, e constatam que o BF é "um programa com focalização excelente que, com relativamente pouco orçamento, consegue ter efeitos significativos sobre a desigualdade de renda no país" (SOARES, VERAS e RIBAS, 2008, no prelo). Concluem, entretanto, que a análise da PNAD revelou uma subcobertura estimada em aproximadamente 3 milhões de famílias. Calculam que, para elevar o teto de 11 milhões para 14 milhões de família e atingir a meta de segurança alimentar do Fome Zero (programa social mais amplo no qual o Bolsa Família se insere), o custo fiscal passaria de 0,35\% para 0,45\% do PIB, ou de $0,9 \%$ para $1,2 \%$ do gasto público.

As informações sobre a focalização e a subcobertura são relevantes para análise da influência do BF na votação de Lula. Entretanto, seria necessário um esforço extra para tentar isolar subconjuntos da população municipal e inferir efeitos diferenciados do BF sobre suas escolhas eleitorais. Vamos nos ater, por ora,

9 IBGE. PNAD 2006. A Pesquisa investigou o recebimento de dinheiro de programas sociais governamentais das esferas federal, estadual e municipal, e direcionou perguntas para o Programa Bolsa-Família, o Benefício Assistencial de Prestação Continuada e o Programa de Erradicação do Trabalho Infantil - PETI.

10 Ver também Soares et al (2006). 
SOARES, G. A. D., TERRON, S. L. Dois Lulas: a geografia eleitoral...

à identificação de concentrações geográficas significativas de municípios onde a contribuição do BF à economia local é mais alta do que nos demais. Investigaremos se estas regiões guardam alguma similaridade com as regiões onde a votação de Lula aumentou substancialmente.

Utilizamos as estimativas estaduais de rendimento médio mensal domiciliar per capita da PNAD para projetar valores de rendimento domiciliar dos municípios em 2006, uma vez que os disponíveis referem-se a 2000. Ajustamos o valor municipal pelo respectivo aumento estadual ocorrido entre 2000 e 2006 (Censo 2000 e PNAD 2006). Calculamos o percentual da contribuição mensal per capita do BF sobre esta renda domiciliar municipal estimada, ambos referidos a $2006^{11}$. 0 percentual da contribuição foi bem superior nas regiões nordeste e norte (Tabela 7): aproximadamente $6,1 \%$ na primeira e cerca de 3,1\% na segunda.

Tabela 7 - Número de municípios, percentual da contribuição do BF sobre a renda domiciliar per capita atualizada para 2006, e percentual de pobres segundo o Censo 2000, por região geográfica

\begin{tabular}{|l|c|c|c|}
\hline Região & $\begin{array}{c}\text { Número de } \\
\text { Municípios }\end{array}$ & $\begin{array}{c}\text { BF/Renda } \\
2006(\%)\end{array}$ & $\begin{array}{c}\text { Pobres 2000 } \\
(\%)\end{array}$ \\
\hline N & 449 & 3,1 & 61,3 \\
\hline NE & 1793 & 6,1 & 69,8 \\
\hline SE & 1668 & 1,5 & 32,7 \\
\hline S & 1188 & 0,9 & 28,4 \\
\hline
\end{tabular}

Fontes: IBGE, MDS, Nicolau e Peixoto (2007b). Processamento dos autores.

A análise sobre a tipologia das cidades brasileiras confirma que a contribuição do Bolsa Família aos rendimentos médios locais é bem diferenciada (Tabela 8). O fator BF sobre a renda é bem maior nas categorias de municípios mais pobres, inclusive nos grandes centros urbanos do norte e do nordeste, ou seja, o fator regional vem antes do tamanho da população.

\footnotetext{
11 Uma correção melhor da renda municipal seria possível separando municípios das regiões metropolitanas e municípios auto-representativos do interior dos demais municípios do estado. A PNAD faz uma expansão amostral diferenciada do estado apenas para um número pequeno de municípios (nove regiões metropolitanas). Nestes casos, a tendência é que o aumento do rendimento domiciliar no período tenha sido maior do que a média estadual, e a influência do BF seja um pouco menor do que a calculada. Optamos por manter a estimativa pela média estadual considerando que seja suficiente para capturar a intensidade do fenômeno nas análises de regressão.
} 
Tabela 8 - Percentuais de municípios, população estimada 2006, contribuição do BF sobre a renda domiciliar per capita atualizada para 2006, e pobres segundo o Censo 2000, por tipo de município

\begin{tabular}{|l|c|c|c|c|}
\hline Tipologia & $\begin{array}{c}\text { Municípios } \\
(\%)\end{array}$ & $\begin{array}{c}\text { Pop Estim } \\
2006(\%)\end{array}$ & $\begin{array}{c}(\%) \text { BF/Renda } \\
2006\end{array}$ & $\begin{array}{c}\text { (\%)Pobres } \\
2000\end{array}$ \\
\hline Grande Urbano (Centro-Sul) & 8,3 & 42,5 & 0,7 & 22,8 \\
\hline Grande Urbano (Norte e Nordeste) & 2,2 & 15,3 & 2,2 & 50,0 \\
\hline Médio Urbano - Rural Próspero & 5,8 & 7,5 & 0,5 & 21,1 \\
\hline Médio Urbano - Rural Misto & 14,5 & 16,9 & 3,8 & 58,1 \\
\hline Pequeno Urbano - Rural Próspero & 17,9 & 4,0 & 0,7 & 24,4 \\
\hline Pequeno Urbano - Rural Misto & 51,4 & 13,8 & 4,1 & 57,1 \\
\hline
\end{tabular}

Processamento dos autores.

Fontes: IBGE, MDS, Nicolau e Peixoto (2007b), PPGEO/UFPE - FASE, (Bitoun, 2008).

A auto-correlação espacial da participação do BF na renda é elevada. 0 índice global de Moran foi calculado em I = 0,7487 (significativo a 0,0001, com média -0,0003 e desvio padrão 0,0079). O indicador Moran Local revelou que as contribuições mais altas (categoria alto - alto) se concentram no nordeste e no norte (parcial), e as mais baixas (categoria baixo - baixo) nas regiões centro-oeste, sul e sudeste (parcial), conforme o Mapa 4. 
SOARES, G. A. D., TERRON, S. L. Dois Lulas: a geografia eleitoral...

Mapa 4 - Distribuição espacial e Moran Local do percentual de contribuição do BF sobre a renda domiciliar per capita 2006

\section{PROGRAMA BOLSA FAMILIA 2006: ESTIMATIVA DO \% DE CONTRIBUIÇÄO NA RENDA MÉDIA DOMICILIAR MENSAL DOS MUNICÍPIOS}

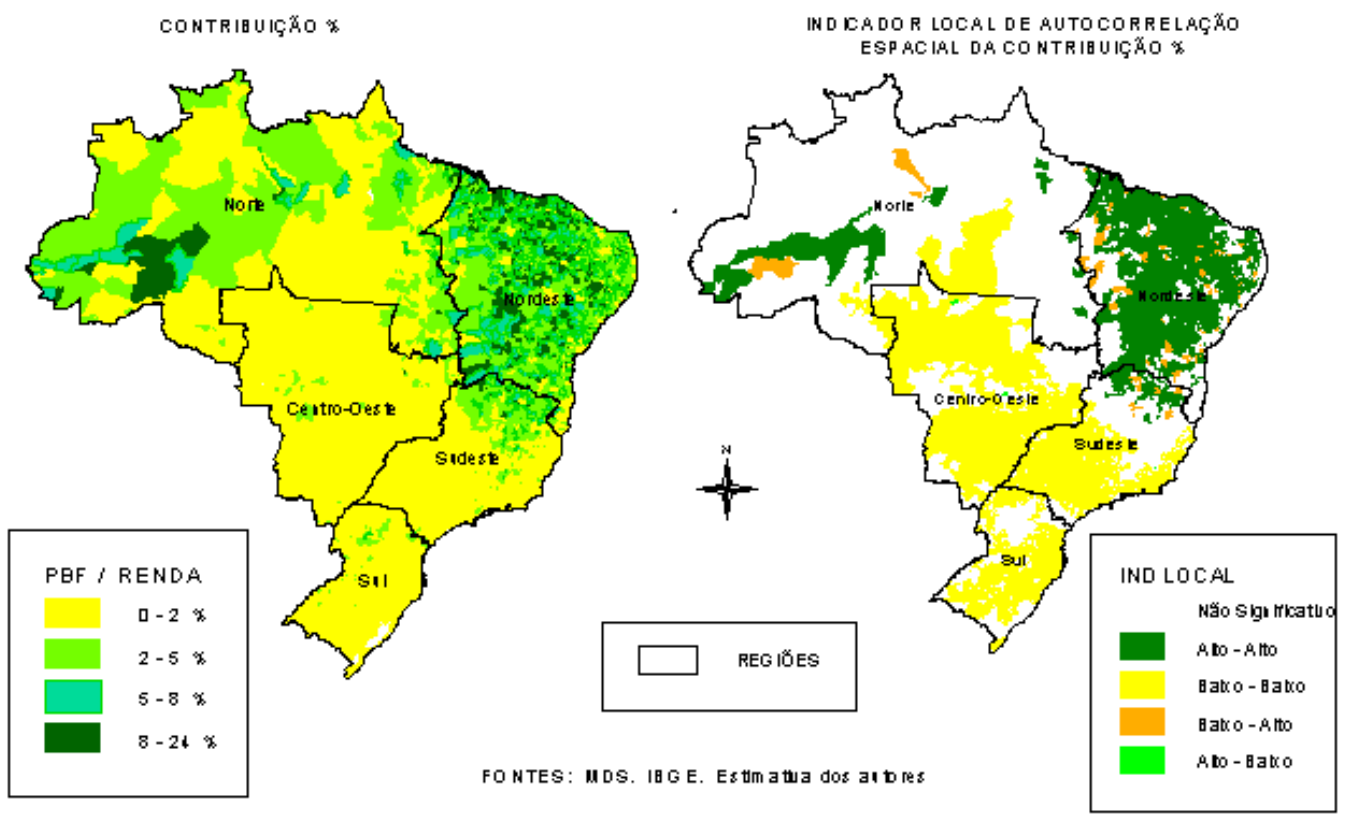

A média de indicadores municipais para o ano 2000, como esperança de vida ao nascer, taxa de analfabetismo e percentual de pobres confirma, como esperado, que a participação do BF no rendimento domiciliar é inversamente proporcional ao desenvolvimento social dos municípios (Tabela 9).

Tabela 9 - Número de municípios, população estimada (2006), média da renda domiciliar per capita municipal (2006), e média de indicadores por município (2000)

\begin{tabular}{|l|c|c|c|c|c|c|}
\hline Agrupamentos & Municípios & População & Renda pc & EVidaNasc & TxAnalf & $\%$ Pobres \\
\hline Alto - Alto & 1246 & 17460 & 144 & 63 & 37 & 73 \\
\hline Baixo - Baixo & 2103 & 48323 & 424 & 72 & 11 & 24 \\
\hline Baixo - Alto & 68 & 98175 & 284 & 65 & 25 & 54 \\
\hline Alto - Baixo & 4 & 4930 & 215 & 69 & 21 & 51 \\
\hline Insignificante & 2143 & 5250 & 244 & 67 & 23 & 53 \\
\hline
\end{tabular}

Fontes: IBGE, Nicolau e Peixoto (2007b). Processamento dos autores. 
Comparamos as estatísticas do BF às diferenças, por município, nos percentuais da votação de Lula em 2006 e 2002. A clivagem regional da diferença de votos fica mais clara nos mapas a seguir.

Mapa 5 - Indicador Moran Local da diferença no percentual de votos de Lula por município no $2^{\circ}$ turno de 2002 e 2006

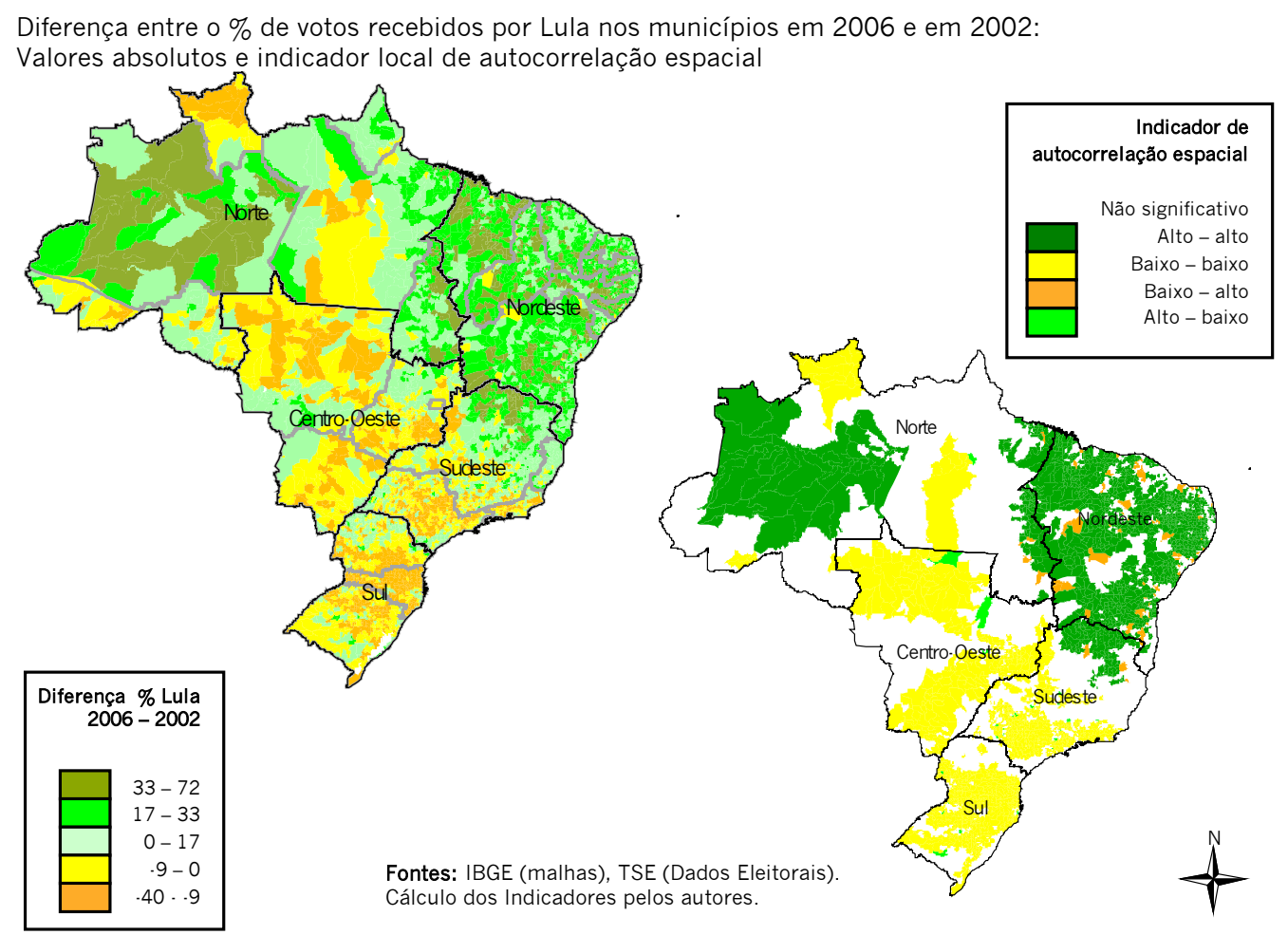

O indicador Moran I das diferenças também é alto: I = 0,7820 (significativo a 0,0001, com média -0,0002 e desvio padrão 0,0080). 0 mapeamento de Moran Local (Mapa 5 da direita) mostra que as maiores diferenças positivas concentraram. se na região nordeste e no estado do Amazonas, e as negativas no centro-sul. Há muita semelhança na concetração espacial dos Mapas 4 (BF/renda) e 5 (diferença na votação 2006 e 2002). Conforme havíamos sugerido anteriormente, a participação do Bolsa Família na economia local deve ter sido o fator decisivo para a nova coesão regional. Segundo essa lógica, dimensionamos este efeito sobre as diferenças dos votos e não sobre o total. 
SOARES, G. A. D., TERRON, S. L. Dois Lulas: a geografia eleitoral...

\section{Inferências}

Nesta seção, testamos as principais conclusões da análise geográficoquantitativa utilizando modelos de regressão. Propomos dois modelos: um sobre a diferença entre a votação de 2006 e 2002 e outro sobre a votação de Lula em 2006. Como as análises espaciais revelaram a presença de auto-correlação espacial nos dados, premissa para a inclusão de controle espacial na regressão, apresentamos os resultados da regressão clássica e da regressão espacial de cada modelo para comparação do ajustamento. Antes, porém, revisamos alguns pressupostos da econometria espacial ${ }^{12}$.

Havendo auto-correlação espacial, os modelos de regressão devem incorporar esta estrutura, pois a dependência entre as observações altera seu poder explicativo. Câmara et al alertam que nestes casos "a significância dos parâmetros é usualmente superestimada, e a existência de variações em larga escala pode até mesmo induzir a presença de associações espúrias" (CÂMARA et al, 2002, p. 29). A hipótese-padrão de observações não correlacionadas pode estar sendo violada, e a auto-correlação espacial presente nos dados se manifesta nos resíduos.

Há vários tipos de regressão que permitem incorporar efeitos espaciais. Tratemos dos modelos com efeitos espaciais globais. Essa classe de modelos supõe que o processo espacial subjacente aos dados é estacionário, e que é possível capturar a estrutura de correlação espacial num único parâmetro. A captura pode atribuir a auto-correlação espacial à variável dependente, ou considerar que os efeitos espaciais são um "ruído" associado ao termo de erro. O modo da captura define duas abordagens.

A primeira abordagem é denominada modelo espacial auto-regressivo misto (spatial autoregressive - SAR) ou modelo de deslocamento espacial (spatial lag mode). É mais apropriada quando o padrão espacial é uma função das observações de vizinhança ( $\mathrm{CHO}$ e RUDOLPH, 2008, p.13) e é formalmente expressa como:

$$
Y=\rho W Y+X \beta+\varepsilon
$$

onde $W$ é a matriz de vizinhança ou proximidade espacial, e o produto WY expressa a dependência espacial em $Y$, e $\rho$ é o coeficiente espacial auto-regressivo. A hipótese nula para a não existência de auto-correlação é que $\rho=0$.

A segunda abordagem, denominada de erro espacial (spatial error mode) ou de modelo condicional auto-regressivo (conditional autoregressive - CAR) é, segundo Cho e Rudolph, mais apropriada a padrões espaciais resultantes de covariatas não mensuradas. $O$ modelo pode ser expresso da seguinte maneira:

$$
Y=X \beta+\varepsilon, \quad \varepsilon=\lambda W+\xi,
$$

\footnotetext{
12 Cf Anselin, 1999; Bailey e Gatrell, 1995; Câmara et al, 2002; Cho e Rudolph, 2008; Kim et al, 2003;
} LeSage, 1999; O'Loughlin, 2003. 
onde $\lambda W$ é a componente do erro com efeitos espaciais, $\lambda$ é o coeficiente autoregressivo e $\xi$ é a componente do erro com variância constante e não correlacionada. A hipótese nula para a não existência de auto-correlação é $\lambda=0$, ou seja, o termo de erro não é espacialmente correlacionado.

Há diagnósticos que podem ser usados para determinar se os dados seguem mais uma ou outra especificação. Anselin recomenda que se inicie a decisão considerando as estatísticas do teste padrão do multiplicador de Lagrange (ML) de cada modelo: ML-Erro (LM-Error) e ML-Deslocamento ( $L M$-Lag) (ANSELIN, 2005, p.197). Caso nenhum dos dois rejeite a hipótese nula deve-se permanecer com os resultados da Regressão OLS clássica. Se um dos testes rejeita e outro não, então se deve adotar a Regressão OLS espacial que rejeita a hipótese nula. Quando ambos rejeitam a hipótese nula, deve-se avaliar as formas robustas dos testes do multiplicador de Lagrange de ambos os modelos, escolhendo o mais significativo, ou seja, o maior valor do ML.

Os estimadores e os diagnósticos tradicionais da regressão não consideram os efeitos espaciais. Assim, os modelos de análise deixam de ser comparáveis pelas medidas tradicionais como as que se baseiam no $\mathrm{R}^{2}$. Câmara et al seguem a literatura e recomendam comparação dos resultados pelo menor valor do critério de informação de Akaike:

"Usualmente a comparação de modelos é feita utilizando o logaritmo da máxima verossomilhança que possui melhor ajuste para os dados observados. O critério de informação de Akaike (A/C) é expresso por:

$$
A / C=\cdot 2^{*} L / K+2 k,
$$

onde LIK é o log de verossimilhança maximizado e $k$ é o número de coeficientes de regressão. Segundo este critério, o melhor modelo é o que possui menor valor de AlC. Diversos outros critérios de informação estão disponiveis, a maior parte dos quais são variações do AlC, com mudanças na forma de penalização de parâmetros ou observações". (CÂMARA et al, 2002, p.35)

Retornamos à discussão inicial na qual Carraro et al discordam dos resultados de Nicolau e Peixoto em dois pontos: os efeitos espaciais foram tratados com dummies regionais na regressão, sendo que é recomendado um tratamento econométrico espacial, e a variável referente ao BF levou em conta toda a população do município, e não apenas a população alvo do Programa. 
SOARES, G. A. D., TERRON, S. L. Dois Lulas: a geografia eleitoral...

Concordamos, por pressuposto conceitual, com a decisão de Nicolau e Peixoto de levar em conta toda a população do município. Fizemos uma regressão espacial sobre as mesmas variáveis do modelo dos autores (Tabela 10) ${ }^{13}$ e constatamos que os coeficientes diminuem no modelo espacial, mas a relação entre eles permanece: o efeito (negativo) da renda domiciliar per capita continua maior do que o efeito (positivo) dos benefícios do PBF 2003-2006 por habitante. Há, como se previa, um redimensionamento das dummies regionais: a correlação aumenta para os municípios do nordeste e diminui para os do norte e do sudeste. O modelo de erro espacial foi escolhido porque apresentou o maior valor do multiplicador de Lagrange (LM). Comparando o critério de informação de Akaike (quanto menor melhor), o ajustamento aos dados observados melhora no modelo de erro espacial. Em suma, a regressão espacial ajusta melhor o modelo aos dados, mas não contradiz as conclusões substanciais dos autores.

Tabela 10 - Modelo 1. Regressão Espacial do Modelo de Nicolau e Peixoto

\begin{tabular}{|l|c|c|}
\cline { 2 - 3 } \multicolumn{1}{c|}{} & Clássica & $\begin{array}{c}\text { Erro } \\
\text { Espacial }\end{array}$ \\
\hline Constante & 53.74 & 51.97 \\
\hline Renda domiciliar mensal per capita, 2000 & 0.05 & .0 .03 \\
\hline Benef. PBF 2003-2006 por hab 2006 & 0.03 & 0.01 \\
\hline Norte (Dummy) & 10.7 & 12.0 \\
\hline Nordeste (Dummy) & 15.0 & 18.7 \\
\hline Sudeste (Dummy) & 8.9 & 7.6 \\
\hline Centro-Oeste (Dummy) * & 1.5 & .0 .5 \\
\hline \multicolumn{2}{|l}{} \\
\hline LM (deslocamento) & 4390.44 & \\
\hline LM (erro espacial) & 4539.23 & \\
\hline \multicolumn{3}{|l}{} \\
\hline R2 & 0.58 & \\
\hline Akaike & 41508.6 & 38140.5 \\
\hline * Não significativa (Centro-Oeste) & \multicolumn{1}{|}{} \\
\hline
\end{tabular}

Processamento dos autores.

Fontes: MDS, IBGE, Nicolau e Peixoto (2007a; 2007b; 2007c), TSE.

\footnotetext{
13 Utilizamos a mesma base de dados de Nicolau e Peixoto (2007a; 2007b; 2007c) para a replicação do modelo de regressão, o que viabilizou a comparação metodológica.
} 
Carraro et al optam por calcular o BF a partir de uma subpopulação do município, os pobres. Esse procedimento exclui a consideração dos efeitos indiretos que o BF exerce sobre a população do município, e gera uma dificuldade metodológica em relação à variável dependente, que se refere aos eleitores do município e não aos eleitores pobres nem aos eleitores indigentes. A pergunta requer considerar até que ponto variáveis baseadas em subconjuntos dos eleitores devem ser usadas para explicar variáveis baseadas no total dos eleitores. Em um modelo de respostas estritamente individuais (excluindo interação e influência entre indivíduos), a variável dependente também deveria ser alterada - a percentagem dos votos dados a Lula pelos pobres e pelos indigentes. Esses dados não existem, e se existissem, a questão colocada seria reduzida à influência do BF sobre o comportamento eleitoral da população pobre. Essas restrições colidem com a conclusão de Carraro et al de que "esses resultados fazem com que o impacto positivo do Bolsa Família, com os devidos controles, não seja tão espetacular e confiável estatisticamente quanto poderia parecer numa primeira análise" (CARRARO et al, 2007).

Os modelos que propomos derivam da análise geográfico-quantitativa, que indicou um impacto diferenciado do BF sobre a economia domiciliar local sugerindo uma forte relação com a mudança nas bases geoeleitorais de Lula de 2002 para 2006. No modelo 2 (Tabela 11), investigamos como as variáveis renda domiciliar e $\mathrm{BF} /$ renda domiciliar, ambas estimadas para 2006, se comportam simultaneamente sobre as diferenças nos percentuais de votos recebidos por Lula nos segundos turnos de 2006 e de 2002.

Tabela 11 - Modelo 2. Regressão sobre a diferença no percentual de votos válidos $2006-2002$ ( $2^{\circ}$ turno)

\begin{tabular}{|l|c|c|}
\cline { 2 - 3 } \multicolumn{1}{c|}{} & Clássica & $\begin{array}{c}\text { Deslocam. } \\
\text { Espacial }\end{array}$ \\
\hline Constante & 12,94 & 6.42 \\
\hline Renda domiciliar mensal per capita, 2006 & 0,04 & $.0,02$ \\
\hline \% Benf Bolsa Família / Renda 2006 & 2,79 & 0,97 \\
\hline \multicolumn{3}{|c|}{} \\
\hline LM (lag) & 3069,59 & \\
\hline LM (error) & 2884,91 & \\
\hline \multicolumn{3}{|l|}{} \\
\hline R2 & 0,62 & \\
\hline Akaike & 42539,9 & 39611,0 \\
\hline
\end{tabular}

Processamento dos autores.

Fontes: IBGE, MDS, Nicolau e Peixoto (2007b), TSE. 
SOARES, G. A. D., TERRON, S. L. Dois Lulas: a geografia eleitoral...

O sentido da correlação mantém-se nas duas regressões: a votação de Lula tende a aumentar com o aumento do BF/renda no município, e a diminuir com o rendimento domiciliar médio. A regressão clássica, entretanto, superdimensiona o efeito do BF/renda: o coeficiente do rendimento domiciliar equivale a $1,4 \%$ do coeficiente do BF/renda; enquanto na regressão espacial equivale a $2 \%$. O teste do multiplicador de Lagrange (LM) indicou a regressão de deslocamento espacial como a mais adequada. A informação de Akaike mostra que o ajustamento melhora na regressão espacial. A variável BF/renda domiciliar tem muito mais peso do que a renda domiciliar per capita. Se fosse possível manter constante o efeito da renda domiciliar, cada $1 \%$ de acréscimo do BF/renda significaria, em média, $1 \%$ de incremento sobre a diferença nos percentuais de votos de Lula no município. Mas e sobre a votação de Lula em 2006, continuaria a ser um determinante?

O modelo 3 encerra a investigação avaliando o comportamento simultâneo das variáveis BF/renda domiciliar 2006, renda média domiciliar 2006, taxa de urbanização 2000 e a votação de Lula no município em 2002 (\% sobre os votos válidos).

$\mathrm{Na}$ análise geográfico-quantitativa, procuramos inferir o comportamento do eleitor urbano na votação de Lula usando a classificação dos centros urbanos dada pela tipologia das cidades brasileiras. As médias de votos em Lula baixaram com o tamanho dos centros urbanos, independente da prosperidade dos espaços rurais, ou seja, aparentemente Lula manteve sua tradição de ser mais votado pelo eleitorado urbano, principalmente o das grandes metrópoles (Tabela 5). Nesta regressão, investigamos a tendência do eleitorado urbano utilizando a taxa de urbanização dos municípios (população que reside nos quadros urbanos - cidades e vilas - municipais).

Analisamos, sob vários aspectos, a inversão geográfica das bases geoeleitorais, mas será que, ao nível nacional, Lula perdeu o apoio dos que o elegeram em 2002? A votação de Lula em 2002 foi incluída na regressão para estimar este efeito. Ainda que a regressão seja espacialmente controlada, inserimos dummies para explicitar o efeito regional relativo. 0 uso de regressões espaciais não invalida o artifício das dummies; o que não se recomenda é o controle dos efeitos espaciais exclusivamente pela inclusão de dummies nas regressões lineares. Neste caso específico as duas situações podem ser facilmente confundidas por que a regionalização criada pelo BF é territorialmente muito próxima dos limites das regiões geográficas tradicionais.

O efeito do BF/renda 2006 continua sendo o fator mais forte e, junto com as dummies nordeste e norte, confirma que o BF influiu regionalmente sobre a votação de Lula (Tabela 12). As bases eleitorais de 2002 continuam apoiando Lula, pois o coeficiente relativo à variável percentual de votos em 2002 é o segundo fator mais forte. Ainda existe uma associação positiva com a urbanização dos municípios. A 
votação decresce com o incremento na renda domiciliar, mas é uma relação menos intensa do que as anteriores.

Tabela 12 - Modelo 3. Regressão sobre o percentual de votos válidos em Lula, $2^{\circ}$ turno, 2006

\begin{tabular}{|c|c|c|}
\hline & Clássica & $\begin{array}{c}\text { Erro } \\
\text { Espacial }\end{array}$ \\
\hline Constante & 30.08 & 33.27 \\
\hline $\begin{array}{l}\text { Renda domiciliar mensal per capita, } \\
2006\end{array}$ & $.0,04$ & $.0,02$ \\
\hline Bolsa Família / Renda 2006 & 1,63 & 0,81 \\
\hline Taxa de Urbanização, 2000 & 0,06 & 0,04 \\
\hline$\%$ Votos Validos Lula, $2^{\circ} \mathrm{T} \cdot 2002$ & 0,47 & 0,37 \\
\hline Norte (Dummy) & 9,82 & 11,33 \\
\hline Nordeste (Dummy) & 12,69 & 17,13 \\
\hline Sudeste (Dummy) & 6,07 & 6,01 \\
\hline Centro-Oeste (Dummy) ${ }^{*}$ & 0,1 & $.0,79$ \\
\hline LM (lag) & 3322,46 & \\
\hline LM (error) & 3530,93 & \\
\hline $\mathrm{R} 2$ & 0,70 & \\
\hline Akaike & 39655,8 & 36824,5 \\
\hline * Não significativa (Centro-Oeste) & & \\
\hline
\end{tabular}

Processamento dos autores.

Fontes: IBGE, MDS, Nicolau e Peixoto (2007b), TSE.

A qualidade do ajuste da regressão pode ser analisada pelo mapeamento dos resíduos: uma alta concentração de resíduos positivos, ou negativos, numa região do mapa é sinal de que as estimativas do modelo distanciaram-se mais das observações devido à presença de auto-correlação espacial. Moran Global e Local indicam se o modelo é ou não capaz de assimilar diferenças regionais sistemáticas nas relações ou tendências espaciais contínuas. Analisamos os resíduos das duas regressões do modelo 3. Moran I revelou uma alta concentração espacial nos resíduos da regressão clássica $(I=0,4757)$. O valor próximo de zero $(I=-0,504)$ comprovou que os efeitos espaciais constantes dos resíduos foram praticamente eliminados na regressão de erro espacial. O mapeamento dos valores de Moran Local dos resíduos das duas regressões (Mapa 6) mostra como a hipótese padrão de observações não correlacionadas pode ter sido violada na regressão clássica, já que a auto-correlação espacial presente nos dados se manifestou nos resíduos. 
SOARES, G. A. D., TERRON, S. L. Dois Lulas: a geografia eleitoral...

Mapa 6 - Indicador Moran Local dos resíduos do Modelo 3

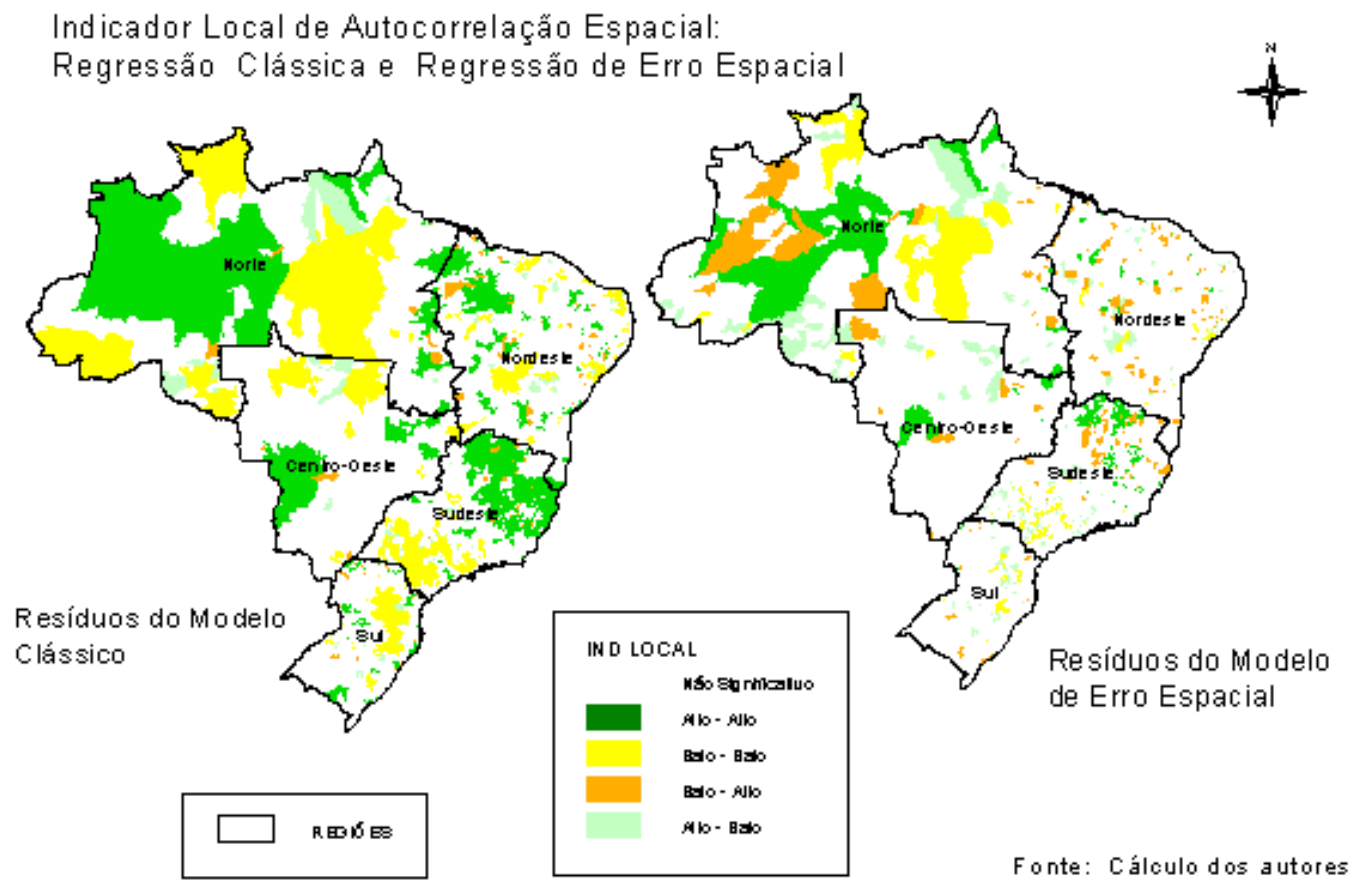

Conclusões

As análises de eleições e de reeleições não são iguais. Na reeleição, o voto pode ter vinculação com o desempenho anterior do candidato. Há elementos informativos e cognitivos disponíveis para uma avaliação baseada no desempenho. A expressão americana eleitoralmente consagrada, running on the record, refere-se exatamente a candidatos que enfatizam seu desempenho como critério para a avaliação dos eleitores. A eleição para governador do Distrito Federal, em 1998, ofereceu uma excelente oportunidade para isso, pois os dois principais candidatos eram o governador e um ex-governador e uma pesquisa de campo mostrou que as políticas públicas tiveram muito peso nas decisões (SOARES, 2000).

A eleição presidencial de 2006 ofereceu outra. A competição de um presidente e um ex-governador introduziu outra variável, que tem tradução espacial: record de um é nacional, mas o do ex-governador é estadual. No foco dos records estão os programas sociais de transferência direta de renda. Lula derrotou o exgovernador de São Paulo, Geraldo Alckmin, no segundo turno, com praticamente o mesmo percentual de votos que o elegeu em 2002 (respectivamente 60,8\% e $61,3 \%$ ). As bases geoeleitorais, entretanto, mudaram significativamente. 
Analisamos a geografia eleitoral da reeleição de Lula explorando conceitos, métodos e técnicas de análise geoespacial. Mobilizamos a discussão teóricoconceitual da geografia eleitoral para a análise político-eleitoral. Testamos o potencial e confirmamos a contribuição que a análise geoespacial e a econometria espacial trazem ao estudo do comportamento eleitoral. Procuramos acrescentar ao que já se sabia sobre 2006 com relação à mudança das bases eleitorais de Lula entre 2002 e 2006, os conceitos de base geoeleitoral, coesão regional e vulnerabilidade regional.

Os resultados revelaram um novo padrão na distribuição espacial dos votos. Confirmaram que Lula ainda recebe o apoio de suas bases anteriores, mas indicaram que os blocos regionais de municípios de alta votação em 2002 perderam a coesão em 2006, tornando-se mais vulneráveis. Desfez-se a hegemonia de Lula em bases geoeleitorais tradicionalmente coesas, como os territórios metropolitanos mais populosos do sul e sudeste e a região de municípios do sudoeste do Paraná e oeste de Santa Catarina.

As análises espaciais delimitaram, e as regressões dimensionaram, uma nova e extensa coesão regional ao redor de municípios menos populosos e mais pobres, cujas dimensões territoriais ultrapassam as fronteiras estaduais e regionais. Mostraram, entretanto, que o ganho foi maior em extensão territorial do que em tamanho do eleitorado. Confirmaram que a participação do Bolsa Família sobre a renda local foi um determinante deste novo contorno das bases geoeleitorais e o fator com maior peso na explicação da votação municipal.

Fica a pergunta: de que modo essa dinâmica se fará sentir na próxima eleição presidencial? Será o Bolsa Família capaz de garantir e até ampliar em 2010 a coesão regional de 2006? Até o momento sabemos que o esforço de 2006, cerca de $0,35 \%$ do PIB e 0,9\% do gasto público, se reverteu em êxito eleitoral e expansão das bases geoeleitorais de Lula. Há que se considerar que diversos fatores interagem de maneira complexa nos resultados eleitorais, entretanto, nosso estudo aponta para a tendência de continuidade dos efeitos regionais de coesão de um pleito para outro, confirmando os pressupostos do contextualismo geográfico. Isto nos leva a crer que o Bolsa Família continuará relevante para a geografia eleitoral de 2010, inclusive com possibilidade de expansão da coesão regional estabelecida entre os municípios. 
SOARES, G. A. D., TERRON, S. L. Dois Lulas: a geografia eleitoral...

Referências Bibliográficas

ANSELIN, L. Spatial Econometrics. Center for Spatially Integrated Social Science - CSSI working paper, 1999. Disponível em:

<http://www.csiss.org/aboutus/presentations/\#anselin>. Acesso em: 18 mar. 2007.

Exploring Spatial Data with GeoDaTM: A Workbook. CSSI, 2005. Disponível em:

<https://www.geoda.uiuc.edu/documentation/tutorials>. Acesso em: 25 mar. 2007.

BAILEY, T. C.; GATRELL, A. C. Interactive Spatial Data Analysis. $1^{\text {a }}$ ed. England: Longman. 1995.

BITOUN, J. PPGEO/UFPE \& FASE. Tabela_geral corrigida\&revisada_01_03_07.x/s.

Recife,2008. Excel for windows.

CÂMARA, G. et al. Análise espacial de áreas. In: FUCKS, S. D. et al. Análise espacial de dados geográficos. $1^{a}$ ed. São José dos Campos: INPE, 2002.

CARRARO, A. et al. "It is the economy, companheiro!": uma análise empírica da reeleição de Lula com base em dados municipais. In: Encontro de Economia da Região Sul, 10, 2007, Porto Alegre-RS. Disponível em: <http://www.pucrs.br/face/ppge/anpecsul/5-07.pdf>. Acesso em: 15 fev. 2008.

CHO, W. K. T.; RUDOLPH, T. J. "Emanating Political Participation: Untagling the Spatial Structure Behind Participation". British Journal of Political Science, vol.38, n², Apr. 2008.

CSISS. GeoDa, 3.2.0 RC 1: software do tipo Geographic Information System. Center for Spatially Integrated Social Science 2005.

ESRI. ArcView GIS, 3.2 a: software do tipo Geographic Information System. Environmental Systems Research Institute, 2000.

ETHINGTON, P. J.; MCDANIEL, J. A. "Political Places and Institutional Spaces: The Intersection of Political Science and Political Geography". Annual Review of Political Science, vol.10, $\mathrm{n}^{\circ} 1,2007$.

HUNTER, W.; POWER, T. J. "Rewarding Lula: Executive Power, Social Policy, and the Brazilian Elections of 2006". Latin American Politics \& Society, vol.49, $\mathrm{n}^{\circ} 1$, Spring 2007. 
IBGE. Contagem da População 2007. Instituto Brasileiro de Geografia e Estatística, 2007. Disponível em: <www.ibge.gov.br>. Acesso em: 25 mar. 2008.

KIM, J.; ELLIOT, E.; WANG, D. M. "A spatial analysis of county-level outcomes in US Presidential elections: 1988-2000". Electoral Studies, vol.22, n²4, Dec. 2003.

LESAGE, J. P. The Theory and Practice of Spatial Econometrics. Econometrics Toolbox: by James P. LeSage, 1999. Disponível em: <http://www.spatialeconometrics.com/html/sbook.pdf>. Acesso em: 05 Mai. 2007.

MARQUES, R. M. et al. Discutindo o papel do Programa Bolsa Família na decisão das eleições presidenciais brasileiras de 2006. In: Encontro Nacional de Economia Política, 12, 2007, São Paulo. Disponível em: CD Rom do XII Encontro Nacional de Economia Política.

NICOLAU, J.; PEIXOTO, V. "As Bases Municipais da Votação de Lula em 2006". In: REIS VELLOSO, J.P. (coord.). Quem elegeu Lula? Cadernos do Fórum Nacional, n6. fev. 2007a.

IUPERJ. Dados 2006 Presidente Artigo 27. sav. Rio de Janeiro, 2007b. SPSS

for windows.

. Uma disputa em três tempos: uma análise das bases municipais das eleições presidenciais de 2006. In: Encontro Anual da ANPOCS, 31, 2007c, Caxambu-MG. Disponível em: <http://jaironicolau.iuperj.br/artigos.html>. Acesso em: 10 jan. 2008.

O'LOUGHLIN, J. Spatial Analysis in Political Geography. In: AGNEW, J. et al. A Companion to Political Geography. 1ª ed. Oxford: Basil Blackwell, 2003.

PATTIE, C.; JOHNSTON, R. Putting Voters in their Place: Geography and Elections in Great Britain. $1^{\text {a }}$ ed. Norfolk, UK: Oxford, 2006.

PPGEO-UFPE; FASE. Classificação (tipologia) das cidades brasileiras. Observatório das Metrópoles, 2005. Disponível em: <http://web.observatoriodasmetropoles.net/>. Acesso em: 17 mar. 2008.

SANTOS, W. G. "Grotões e coronéis vivem de estatística". Valor Econômico, São Paulo, 15 dez. 2006.

SMITH, M. J.; GOODCHILD, M. F.; LONGLEY, P. A. Geospatial Analysis: a comprehensive guide to principles, techniques and software tools. UK: Matador, 2007. 
SOARES, F. V. et al. "Cash Transfer Programmes in Brazil: Impacts on Inequality and Poverty". UNDP International Poverty Centre, Working Paper 21, 2006.

SOARES, G. A. D. "Em Busca da Racionalidade Perdida". Revista Brasileira de Ciências Sociais, vol.15, $\mathrm{n}^{\circ} 43,2000$.

"A nova geografia do voto". O Globo, Rio de Janeiro, 09 out. 2006.

SOARES, S.; VERAS, F.; RIBAS, R. O Paradoxo do Bolsa Família: Excelente Focalização e Subcobertura. IPEA. 2008. Texto para Discussão a ser publicado em:

<http://www.ipea.gov.br/default.jsp>.

ZUCCO, C. A governabilidade num segundo governo Lula. In: Encontro da Associação de Ciência Política do Uruguay (AUCIP), 1, 2006, Montevideo. Disponível em:

<http://czucco.bol.ucla.edu/aucip.pdf>. Acesso em: 15 fev. 2008.

. The President's 'New' Constituency: Lula and the Pragmatic Vote in Brazil's 2006 Presidential Elections. Journal of Latin American Studies, vol.40, n¹, p. 29-49, Feb. 2008.

ZUCKERMAN, A. S. (Ed.). The Social Logic of Politics. $1^{\text {a }}$ ed. USA: Temple University Press, 2005.

Gláucio Ary Dillon Soares · soares.glaucio@gmail.com

Sonia Luiza Terron·sterron@iuperj.br

Recebido e aprovado para publicação em agosto de 2008. 